\title{
SECUELAS POST-INFECCION POR ADENOVIRUS EN NIÑOS: EVALUACION CON TOMOGRAFIA COMPUTADA
}

Drs José D. Arce V(1), Roberto Mondaca $A^{(2)}$, Rodolfo Mardones ${ }^{(2)}$, Luis F. Velozo P(3), Genoveva Parra O(4).

1. Servicio de Radiología. Clínica Santa María. 2. Servicio de Radiología. Hospital Roberto del Río. 3. Servicio Anatomía Patológica. Hospital Roberto del Río. 4. Servicio Broncopulmonar. Hospital Roberto del Río.

\begin{abstract}
Introduction. Severe pulmonary involvement may occur after adenovirus infection and longstanding pulmonary sequelae may observe essentially bronchiolitis obliterans (BO). Objective. To evaluate the CT findings in children who had suffered adenovirus infection. Patients and method. We reviewed retrospectively the CT findings in 23 children with proven adenovirus infection, excluding those patients with other pulmonary diseases. Results. In all patients CT showed findings consistent with bronchiolitis obliterans, characterized by diffuse or multifocal air trapping with a secondary mosaic attenuation (23 patients), peribronchial thickening and decreased vascularization in the involved areas (23 patients), bronchiectasis (23 patients) and segmental atelectasis (19 patients). In 3 patients the collapsed lobe was resected and histology showed $B O$. Conclusions. CT was helpful in the study of patients who had suffered adenoviruses infection and showed findings consistent with $\mathrm{BO}$ in all of them. This infection could be related with a greater predominance of genome type $7 \mathrm{~h}$ in South American countries. The amount of pulmonary collapse could be related with the more aggressive serotype of adenovirus in our country.
\end{abstract}

Key words: Adenovirus, Bronchiolitis obliterans.

Resumen: Introducción. La infección pulmonar por adenovirus en el niño, puede presentar una amplia variedad de manifestaciones clínicas, y ser causa de hospitalizaciones prolongadas. Como complicaciones pueden ocurrir la muerte o el desarrollo de graves secuelas pulmonares. El diagnóstico se plantea sobre la base de los antecedentes clínicos y se

Arce JD y cols. Secuelas post-infección por adenovirus en niños: Evaluación con tomografía computada. Rev Chil Radiol 2002; 8: 154-163.

Correspondencia. Dr. J. D. Arce V. Servicio de Radiología: Clínica Santa María. Avda. Santa María 0410. Santiago.E-mail jarce@csm.cl confirma con estudio de inmunofluorescencia en secreción faríngea. Los estudios de imágenes son importantes en el diagnóstico y control de la evolución de la enfermedad fundamentalmente la radiografía $(R x)$ de tórax y la tomografía computada (TC). Objetivo. Presentar nuestra experiencia con el uso de TC en niños que presentaron infección por adenovirus, con énfasis en las secuelas. Se destaca además la relación de la enfermedad con la existencia de la un tipo genómico viral (7h). Pacientes y método. Se revisó retrospectivamente 24 TC de 23 niños en quienes se demostró infección por adenovirus, en el periodo agudo, a través de inmunofluorescencia indirecta en muestra de secreción faríngea y en quienes se descartó otras patologías pulmonares. Resultados. En todos los pacientes la TC mostró alteraciones compatibles con bronquiolitis obliterante y los hallazgos principales correspondieron a atrapamiento aéreo (23 pacientes, 24 TC) que fue difuso o multifocal dando un patrón de atenuación en mosaico; engrosamiento peribronquial y disminución del diámetro y cantidad de los vasos en el área comprometida (23 pacientes, $24 \mathrm{TC}$ ), bronquiectasias (15 pacientes, 16 TC). El compromiso pulmonar fue bilateral en todos los pacientes. En un número importante de casos se encontró atelectasia cicatrizal (19 pacientes; 20 TC) con colapso pulmonar. En 3 de ellos se resecó el segmento pulmonar colapsado y el estudio histológico demostró bronquiolitis constrictiva. Pensamos que esta manifestación es resultado de una mayor agresividad del tipo genómico de adenovirus predominante en nuestro país. Conclusiones. La TC de tórax fue de utilidad en la evaluación y determinación de las secuelas pulmonares de pacientes con antecedentes de neumopatía por adenovirus y mostró hallazgos compatibles con bronquiolitis obliterante en todos los casos de nuestra serie. Destaca la relación de esta infección con un tipo genómico viral (7h), prevalente en el área sur de Sudamérica.

Palabras claves: Adenovirus, Bronquilitis obliterante. 


\section{Introducción}

El adenovirus puede afectar la vía aérea de adultos y niños. La infección en el niño puede presentar una amplia variedad de manifestaciones clínicas, que van desde cuadros respiratorios leves hasta neumonías graves. Estas últimas son causa de hospitalizaciones prolongadas, ingreso a unidades de cuidado intensivos y eventualmente muerte ${ }^{(1-3)}$ o bien de graves secuelas pulmonares. Algunos serotipos como el 3, 7 y 21 pueden asociarse a infecciones graves en lactantes y niños menores ${ }^{(3,4)}$.

Estudios de seguimiento en infección por adenovirus han demostrado que los niños sobrevivientes pueden presentar secuelas que pueden llegar hasta un daño pulmonar morfológico extenso y crónico ${ }^{(5-7)}$, además de importantes alteraciones funcionales $^{(8,9)}$.

El tipo genómico viral $7 \mathrm{~h}$ ha sido detectado en Sudamérica incluyendo el sur de Brasil, Argentina, Uruguay y Chile y se ha asociado a infecciones graves por este mismo germen ${ }^{(10-14)}$.

Pocos trabajos han demostrado las alteraciones secuelares debidas a infección por adenovirus en estudios radiológicos simples ${ }^{(5,7)}$ y menos las alteraciones visibles en tomografía computarizada (TC). Hay algunos estudios con esta última técnica que dan el antecedente de bronconeumonía en la infancia sin determinar su exacta etiología, entre estos se incluyen algunos estudios en japonés ${ }^{(15,16)}$ y otros en que las alteraciones son producidas por diferentes agentes infecciosos entre los cuales se incluye el adenovirus ${ }^{(17-19)}$.

\section{Pacientes y método}

Se efectuó análisis retrospectivo de TC de pacientes enviados a estudio con el antecedente de infección por adenovirus, que fue confirmada durante el cuadro agudo mediante immunofluorescencia indirecta (IFI) en muestras obtenidas de secreción faríngea. Las TC fueron efectuadas en los servicios de Radiología del Hospital Roberto del Río y Clínica Santa María entre Julio de 1993 y Agosto del 2002.

Se descartaron todos aquellos casos con patología pulmonar subyacente tales como: Asma, fibrosis quística, disquinesia ciliar, displasia broncopulmonar, síndrome de Williams-Campbell o deficiencia inmunitaria.

Los pacientes presentaban diferentes grados de sintomatología al momento del examen y en algunos de ellos solo existía el antecedente de infección por adenovirus.

Se recolectaron 24 estudios realizados en 23 pacientes. En nuestra revisión encontramos 16 niños del sexo masculino $(69.5 \%)$ y 7 del sexo femenino $(30.5 \%)$. La edad promedio en que se efectuó el diagnóstico de infección por adenovirus, confirmado por IFI, fue de 19,5 meses (Rango: 6 meses a 9 años 6 meses) y la edad promedio de la TC 41,7 meses (Rango: 1 año 1 mes a 15 años). Hubo un intervalo entre el diagnóstico por IFI y el momento de la TC que en promedio fue de 22,2 meses (Rango: 2 meses a 144 meses).

Los estudios fueron efectuados con técnica secuencial, en 4 casos y de alta resolución (AR) en 20 casos con cortes de $1 \mathrm{~mm}$ y reconstrucción con algoritmo de alta frecuencia espacial. Los equipos usados fueron, Somaton Plus 4, Somaton CR (Siemens, Erlagen, Alemania) y Shimadzu SCT7000. Desde el año 2001 el protocolo de estudio fue ajustado usando mAs menores de 80 (Rango 80-40) y $120 \mathrm{Kv}$ comenzando con estudio helicoidal, seguido de cortes finos y procesamiento de alta resolución (AR) en las zonas en que se demuestra patología.

En 18 niños menores de 6 años los estudios fueron efectuados en volumen corriente y en los 5 mayores de 6 años en inspiración. En 2 de estos últimos pacientes los estudios realizados incluyeron algunos cortes en inspiración-espiración. No se utilizó medio de contraste. En niños menores de 2 años se usó sedación con Hidrato de Cloral en dosis de 50$100 \mathrm{mg}$ por $\mathrm{Kg}$ y en 4 de los primeros casos el examen se efectuó con anestesia general.

Los hallazgos de TC se clasificaron de acuerdo a los criterios previamente publicados en la literatura y sabido el hecho que el adenovirus determina una bronquiolitis obliterante (BO)constrictiva ${ }^{(5,6,17,20-22)}$. De esta manera, éstos se agruparon en:

1. Signos directos: a) Engrosamiento de la pared bronquiolar, b) Impactación mucosa del lumen bronquiolar.

2. Signos indirectos: a) Atrapamiento aéreo, definido como áreas de menor atenuación pulmonar, que llamamos difuso cuando compromete un lóbulo o todo un pulmón (Figura 1); o multifocal cuando compromete sectores de un lóbulo determinando el patrón descrito como atenuación en mosaico (Figura 2); b) disminución de volumen pulmonar y c) disminución del diámetro de los vasos hiliares o periféricos.

3. Otros hallazgos no relacionados directamente con la afectación bronquiolar incluyen: a) engrosamiento de la pared bronquial, b) bronquiectasias, y c) compromiso del espacio aéreo por sobreinfección agregada.

Se estudio con especial atención la vía aérea para descartar cualquier causa obstructiva.

\section{Resultados} Tabla I.

Los hallazgos tomográficos se resumen en la

Uno de los principales hallazgos fue el atrapamiento aéreo visible en todos los casos. Se 

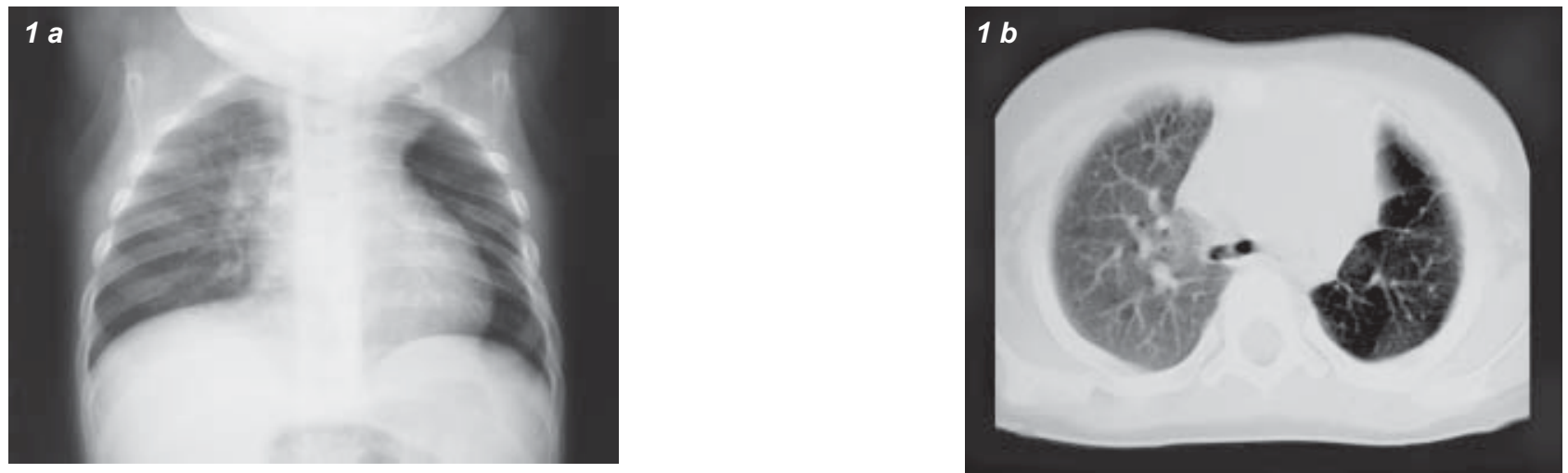

Figura 1 a, b. Paciente del sexo masculino de 1a 11meses con atrapamiento aéreo difuso que compromete el pulmón izquierdo. a: Rx de tórax demostrando una hipertransparencia del pulmón izquierdo, disminución de la vascularización e hilio pequeño. b: TAC. Corte en lóbulo superior derecho demostrando un atrapamiento aéreo difuso. Cortes inferiores demostraron compromiso multifocal en pulmón derecho.

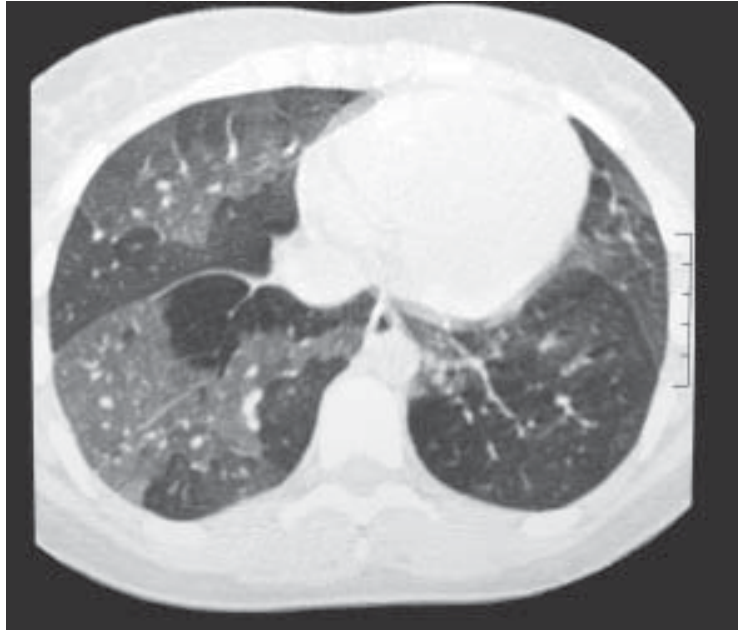

Figura 2. Paciente del sexo femenino de 12 años. Corte efectuado en espiración que demuestra áreas de atrapamiento aéreo multifocal, que determinan un patrón de atenuación en mosaico. Obsérvese la escasa cantidad de vasos en las zonas de menor atenuación. tabulo en forma separada de acuerdo al compromiso predominante como difuso o multifocal, sin embargo el compromiso llamado difuso alternó siempre con áreas de compromiso multifocal en zonas del mismo pulmón o del contralateral. En todos los casos el compromiso fue bilateral. El compromiso multifocal al afectar sectores de un lóbulo y alternar con pulmón normal, da el patrón descrito como atenuación en mosaico que se manifiesta mejor en espiración y con técnica de alta resolución (Figura 2).

Observamos una alta incidencia de atelectasia cicatrizal, que en 3 de los casos en que se efectuó resección del segmento de pulmón afectado se confirmó en ella la presencia de bronquiolitis obliterante constrictiva en áreas vecinas a las que demostraban daño crónico pulmonar con bronquiectasias (Figura 3).

Se consignó como desviación de mediastino un caso en el cual hubo atelectasia cicatrizal total de un

Tabla I. Bronquiolitis obliterante por adenovirus: Hallazgos en TAC

( $\mathrm{N}=23 ; 24$ estudios)

Atrapamiento aéreo

Difuso $13(55 \%)$

Multifocal 11 (45\%)

Disminución de diámetro de vasos área afectada

Engrosamiento peribronquial

Bronquiectasias

Atelectasia cicatrizal

LSD: 9; LSI: 2; LID: 6; LII: 12; LM: 0; Ling: 1

Disminución de volumen pulmonar

Condensación y Nódulos centrolobulillares

Desviación de mediastino
24

(100\%)

24

24

(100\%)

16

20

$(100 \%)$

(67\%)

(83\%)

20

5

(83\%)

(21\%)

(4\%)

En el caso con dos estudios efectuados al año 11 meses y a los 4 años se repiten sin variaciones los hallazgos de atrapamiento aéreo difuso, atelectasia segmentaria cicatrizal del lóbulo inferior derecho, bronquiectasias y engrosamiento peribronquial (Figura 5). 
pulmón (Figura 4). En los casos tabulados como disminución de volumen pulmonar el desplazamiento del mediastino no fue significativo.

De acuerdo a los criterios de análisis definidos, no encontramos signos directos de bronquiolitis (engrosamiento de la pared bronquiolar, impactación mucosa del lumen bronquiolar).

\section{Discusión}

Las infecciones respiratorias agudas (IRA) son un problema de salud mundial produciendo morbilidad y mortalidad en niños. Los virus son una causa importante de estas.

La infección respiratoria aguda (IRA) por adenovirus es común en niños siendo los serotipos virales más frecuentemente reportados los 3,7 y $21^{(3)}$. Esta infección es endémica en los países del sur de Sudamérica ${ }^{(10-14)}$ y se manifiesta en brotes epidémicos en su mayoría nosocomiales ${ }^{(1,2,4,14)}$. Se ha demostrado en estos países, en estudios epidemiológicos, a partir de 1984 la existencia de un tipo genómico, el $7 \mathrm{~h}^{(4,23)}$, que tiene un mayor potencial patógeno ${ }^{(4,14)}$ y se asocia con neumonías mas graves, hospitalizaciones prolongadas, mayor cantidad de secuelas y muerte especialmente en niños con patología subyacente.

Recientemente se ha comunicado en Japón brotes de infección por adenovirus $7 \mathrm{~h}$ que advierten sobre la diseminación de este tipo genómico a otras partes del mundo(23).

En Chile las IRA son la causa más común de consultas y hospitalizaciones en niños ${ }^{(25)}$. En menores de 2 años hospitalizados en el Hospital Roberto del Río el virus sincicial respiratorio fue causa en un $26.3 \%$ de los casos y el adenovirus en un $12.6 \%$; el primero fue mas aislado en los meses fríos y el segundo se detectó en el curso de todo el año(13). Los serotipos de adenovirus principalmente aislados en este estudio fueron los 1,2 y $7 \mathrm{~h}$, siendo este ultimo responsable de aproximadamente $50 \%$ de los casos.

En nuestra serie la edad promedio al momento de la infección (IFI positiva) estuvo por debajo de los 2 años.

La infección por adenovirus tiene una alta tasa de ataque secundario que es de aproximadamente $55 \%{ }^{(14)}$ y un largo período de excreción que es de hasta aproximadamente 2 meses.

Los motivos de la mayor agresividad de algunas cepas virales no son claros. Se ha encontrado en algunos pacientes con infección por adenovirus, complejos inmunes circulantes conteniendo antígeno adenoviral, depositado en pulmones y riñones en casos fatales. La existencia de valores séricos elevados de interleukina 6 y 8 , además de factor de necrosis tumoral alfa, se ha asociado a casos fatales ${ }^{(26)}$.

La infección viral puede llevar a la resolución sin secuelas, muerte del paciente ${ }^{(1-3)} \mathrm{o}$ bien conducir a una BO constrictiva secuelar ${ }^{(7,21)}$. El compromiso dependerá de la extensión del daño inicial, de la virulencia de la cepa involucrada, de la respuesta inflamatoria del huésped, probablemente a factores genéticos ${ }^{(27)}$ y la edad en que ocurre la infección(8) siendo mas grave en menores de 2 años. La probable patogenia se asocia a la replicación viral intraepitelial con necrosis subsecuente mas la respuesta inmune de parte del paciente ${ }^{(28)}$.

Las secuelas se han descrito en hasta un $60 \%$ de los sobrevivientes de un brote epidémico por adenovirus del tipo $21^{(7)}$. Las alteraciones patológicas más destacadas han sido: una extensa obliteración y estenosis bronquiolar, con colapso pulmonar y áreas de fibrosis. En bronquios de tamaño intermedio y grandes se describen bronquiectasias especialmente dentro de los lóbulos colapsados ${ }^{(6)}$.

Otras causas infecciosas de BO han sido descritas en la edad pediátrica e incluyen sarampión, bordetella pertussis, micoplasma pneumoniae e influenza $A^{(20)}$.

También es causa de BO en la edad pediátrica el trasplante pulmonar, trasplante corazón-pulmón o trasplante de medula ósea. Se describe en estos casos una causa infecciosa en un $10-25 \%$ de los casos e incluyen herpes simplex, citomegalovirus, pneumocystis carinii, mycobacterium chelonae, virus sincicial respiratorio y parainfluenza tipo $3^{(20)}$.

Se ha creado confusión respecto a la definición de BO ya que el termino ha sido usado para describir un síndrome clínico como también dos subtipos de compromiso histológico.

Pensamos que la descripción de Colby y su clasificación es la más adecuada ${ }^{(29,1998)}$. Define como bronquiolitis la inflamación del bronquiolo y establece que al ser este un puente entre el bronquio y alvéolos, ambos muchas veces también serán afectados. De la misma forma al constituir el haz broncovascular una unidad anatómica el compromiso bronquiolar inflamatorio y fibrótico puede conducir a alteraciones vasculares, como lo son la hiperplasia de la túnica media y adventicia, que contribuirán en parte al patrón en mosaico visible en los estudios tomográficos. Los tipos descritos por él son: Enfermedad bronquiolar acompañando a otras patologías (asma, bronquitis crónica), bronquiolitis respiratoria, bronquiolitis celular (necrotizante aguda en el caso de adenovirus), BO con pólipos intraluminales (obliterante proliferativa) y bronquiolitis constrictiva.

Los dos últimos tipos han sido tradicionalmente agrupados como BO. La BO con pólipos intraluminales se asocia a focos de neumonía organizante y se asigna el nombre combinado de BO con neumonía organizante (BOOP) o en ausencia de compromiso alveolar como bronquiolitis obliterante proliferativa ${ }^{(30)}$. La bronquiolitis constrictiva es un com- 


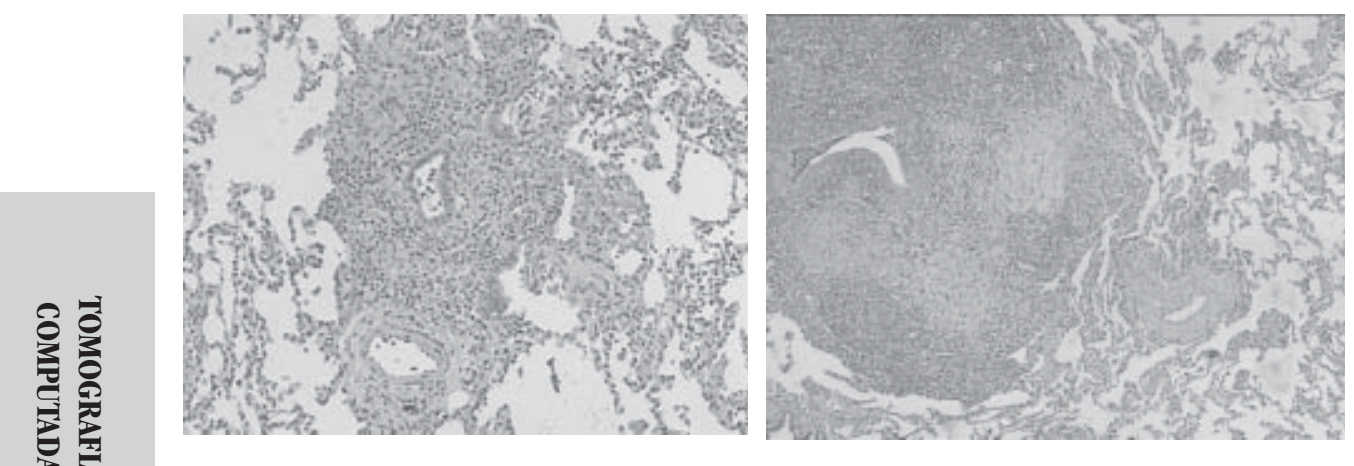

Figura 3 a,b. Estudio histológico en pacientes en que se resecó lóbulos colapsados y con broquiectasias. a: Bronquíolo pequeño con infiltrado linfoide escaso, leve fibrosis peribronquiolar y perivascular. HE $5 x$ b: Bronquíolo con intensa inflamación linfoplasmocitaria $y$ folículos linfoides periféricos, fibrosis y esclerosis vascular. HE $5 x$
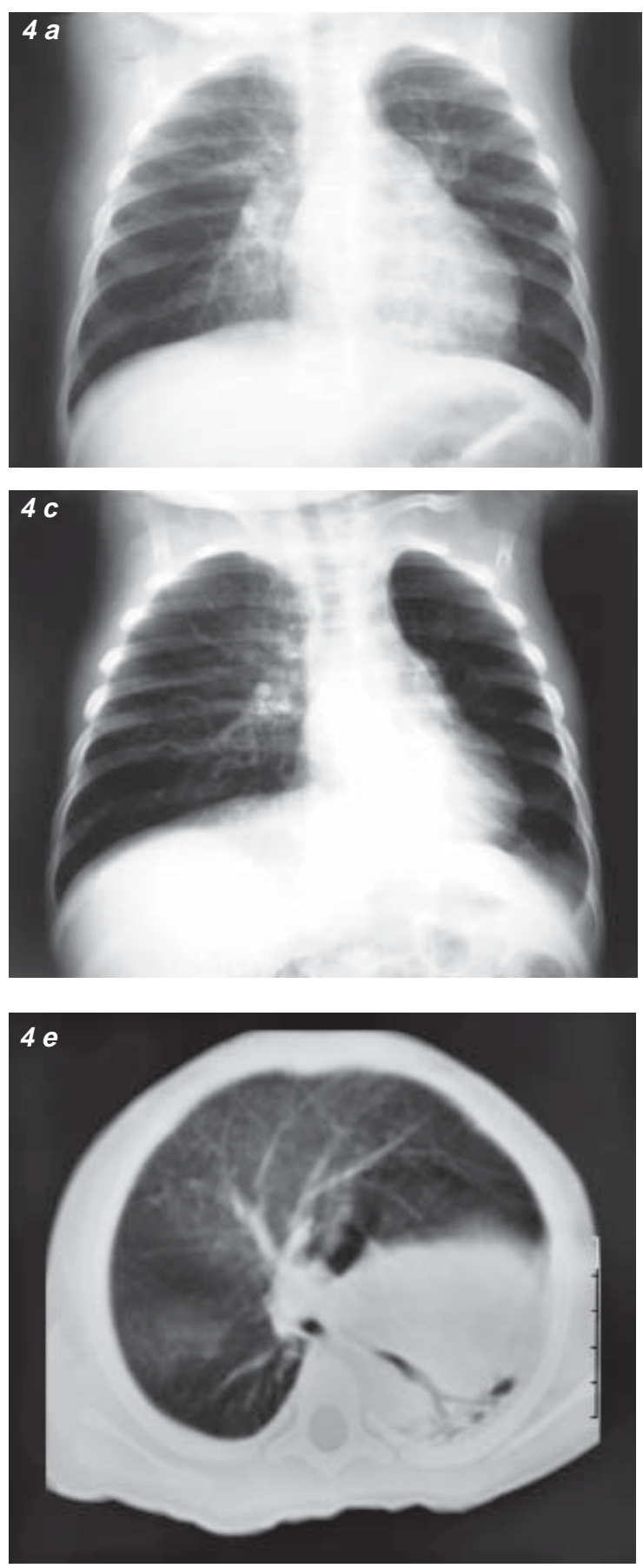
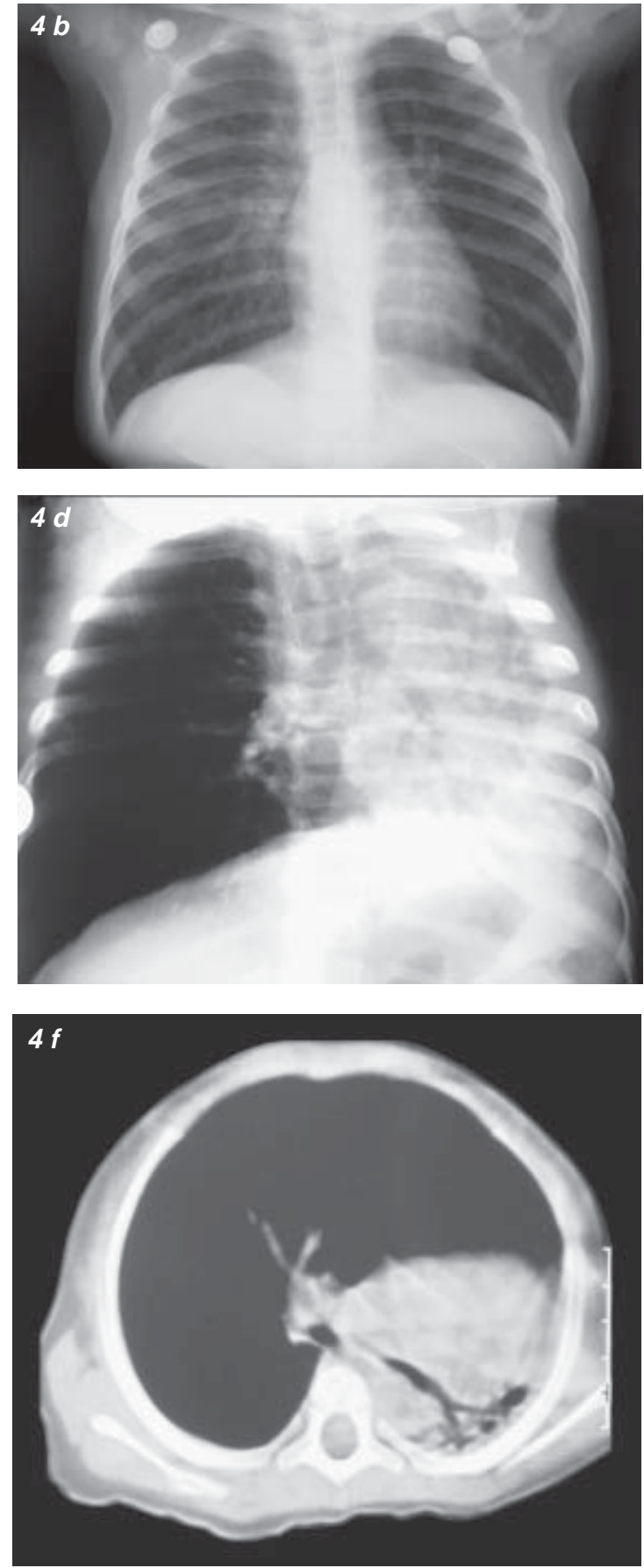

Figura 4 a,b,c,d,e,f. Paciente del sexo femenino con infección aguda a los 11 meses, en quien durante la hospitalización se demuestra un cuadro evolutivo que al cabo de 2 meses lleva al colapso total del pulmon izquierdo. a: Rx de torax a los 11 meses. b: 12 meses. c: 12 meses y 2 semanas. d: 13 meses. e,f: TAC de torax a la edad de 15 meses. 
promiso mas bronquiolar con poco compromiso periférico y con un componente de fibrosis peribronquiolar que llevara a grados variables de obliteración del lumen bronquiolar. Es este tipo histológico el que se relaciona con el cuadro clínico de BO y para él Colby reserva este nombre ${ }^{(29)}$.

La infección por las formas más agresivas de adenovirus en su etapa de curación puede llevar a una bronquiolitis constrictiva en la gran mayoría de los $\operatorname{casos}^{(5,6,17,20,21)}$. Esta manifestación también se ha demostrado en el estudio histológico de algunos casos fatales ${ }^{(1)}$. El cuadro agudo es una bronquiolitis infecciosa necrotizante (bronquiolitis celular) que al examen histológico demuestra necrosis del epitelio bronquial y bronquiolar y un infiltrado mixto de grado variable compuesto por linfocitos y neutrofilos peribronquial e intraepitelial. Hay además algún grado de inflamación intersticial acompañado de diversos grados de atelectasia e hiperinsuflación. En los casos graves sin resultado de muerte, la evolución es hacía la regeneración del epitelio bronquial y bronquiolar, metaplasia cuboidea y epidermoide, bronquioloectasia, mayor inflamación intersticial y fibrosis, formación de folículos linfoides, bronquiolitis obliterativa y a veces áreas de tipo neumonía organizante focal e hiperplasia vascular. La fibrosis insterticial, hiperplasia vascular, bronquiolitis constrictiva y bronquiectasias quedan como secuelas permanentes. El mayor grado de fibrosis representaría el estadio final del compromiso morfológico de la vía aérea y parénquima vecino visualizado en TC como atelectasia cicatrizal.

Esta progresión se comprueba en algunos de nuestros casos en que tuvimos la secuencia evolutiva de imágenes (Figuras 4,5) y en las cuales se demuestra que el compromiso es inmediato post-infección y permanente en el tiempo.

El año 1953 Swyer y James ${ }^{(31)}$ describieron el caso de un niño de 6 años en quien la radiografía de tórax demostró un compromiso unilateral con
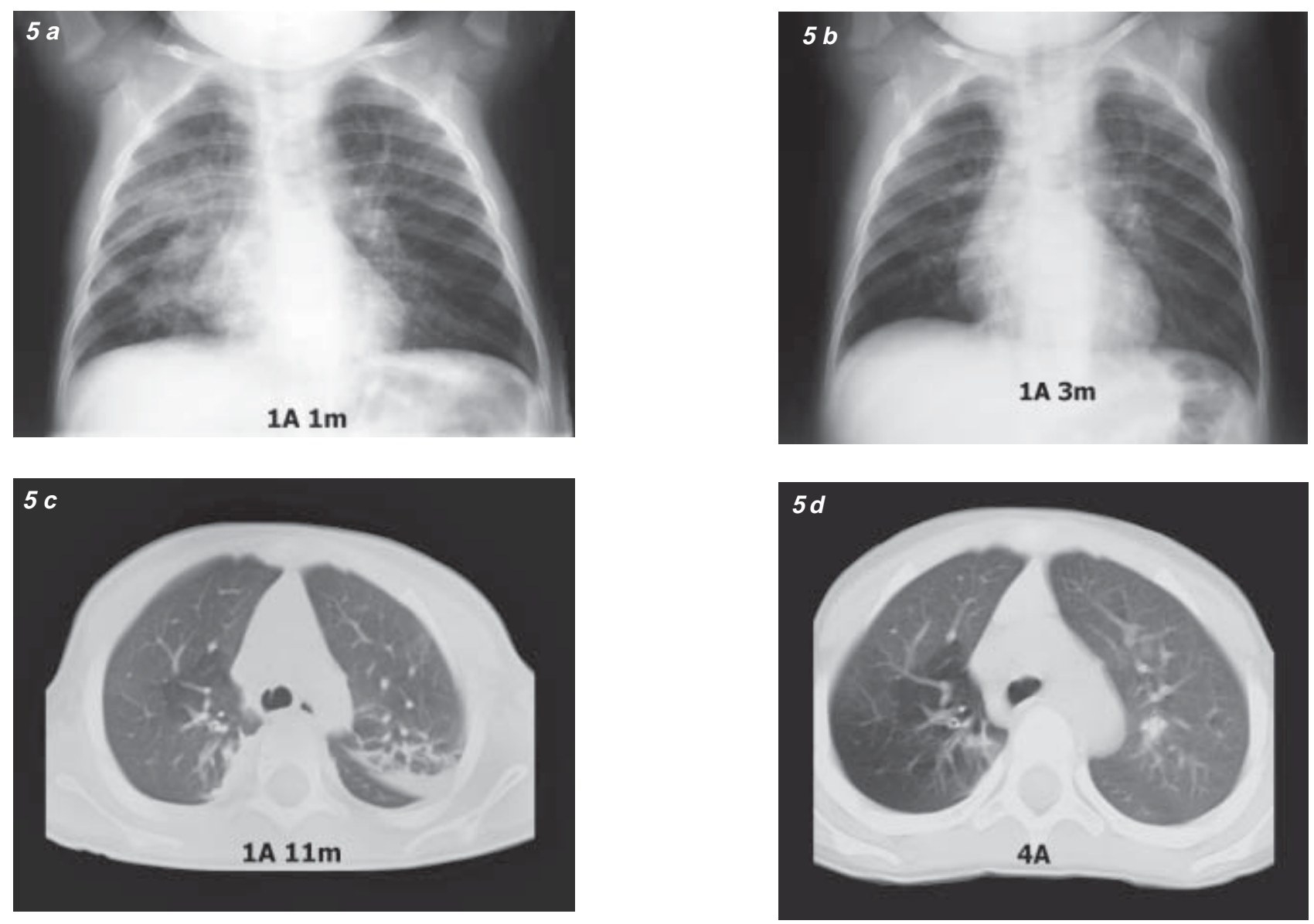

Figura 5 a,b,c,d. Paciente del sexo masculino con cuadro agudo a la edad de 1 año 1 mes. Se demuestra en Rx de tórax un compromiso alveolar que compromete especialmente el pulmón derecho, hay ademas compromiso del lóbulo inferior izquierdo (a). Un control radiográfico 2 meses después del cuadro agudo demuestra disminución de volumen e hipertransparencia que compromete el pulmón derecho (b). En este paciente se efectuaron controles con TAC a las edades de 1 año 11 meses (c) y 4 años (d) demostrando que el compromiso caracterizado por atrapamiento aéreo, engrosamiento peribronquial y disminución del número y calibre de los vasos es adquirido precozmente y no se modifica en el tiempo. La primera TAC fue efectuada bajo anestesia general que explica la atelectasia subsegmentaria a izquierda. 
hipertransparencia y disminución del dibujo vascular, además de una moderada disminución de volumen. En la broncografía observaron una falta de llenamiento de los bronquios periféricos y en la cardioangiografía vasos hiliares y periféricos disminuidos de calibre y en número en el pulmón afectado. La broncoscopía demostró que los bronquios principales eran normales. En este caso se efectuó neumonectomía y el estudio histológico demostró lo que actualmente se describe como BO constrictiva. Destaca el estudio que al examen macroscópico la arteria pulmonar principal era de un calibre mayor que el apreciado en los estudios radiológicos. Ello es hoy reconocido como un fenómeno secundario al atrapamiento aéreo en donde la hipoxia, la retención de $\mathrm{CO} 2$ y la acidosis producen vasoconstricción.

Posteriormente el año 1954 Mac Leod ${ }^{(32)}$ agregó la observación, en 7 casos de pacientes adultos, el atrapamiento aéreo que se manifiesta en las placas obtenidas en espiración.

Los hallazgos de la TC en nuestro estudio comparten los de Swyer y James, y Mc Leod. En estos dos estudios sin embargo y dado a la resolución limitada de los exámenes disponibles se reconoció solo el compromiso unilateral. Con las nuevas técnicas de imagen como lo es la TC hoy podemos reconocer que la afectación es siempre bilateral como lo demuestra nuestro estudio en todos los casos. Previamente en estudios histológicos de necropsias en que se han examinado los dos pulmones esto ha sido también comprobado(6).

Destaca como principal hallazgo tomográfico el atrapamiento aéreo siempre bilateral, de distribución aleatoria y relacionado con la afectación no uniforme de los diferentes segmentos pulmonares por el virus. En su evaluación no se consideraron las áreas de menor atenuación próxima a los planos cisurales y las zonas de relativa menor atenuación en los segmentos apicales de los lóbulos inferiores o el atrapamiento en lobulillos secundarios únicos visibles en algunos individuos normales ${ }^{(33)}$.

La bronquiolitis constrictiva produce un atrapamiento aéreo irreversible a diferencia de otros cuadros como el asma, cuadros infecciosos agudos o hiperreactividad.

En niños menores, al efectuar el estudio en volumen corriente o respiración quieta el volumen pulmonar es menor, de esta forma el parénquima normal presenta una mayor atenuación que en niños mayores o adultos en quienes el examen es efectuado en inspiración. Esto permite demostrar bien el atrapamiento aéreo. Por otra parte la asociación de zonas de mayor transparencia con una menor cantidad de vasos se debe a atrapamiento aéreo o enfermedad vascular, siendo esta última condición rara en niños.

Para patología metastásica está demostrado experimentalmente que la técnica helicoidal en respiración quieta no pierde información respecto a estudios en inspiración ${ }^{(34)}$. Pensamos que un adecuado estudio se puede lograr localizando las áreas de pulmón patológico en estudio helicoidal, idealmente multidetector, y posteriormente reevaluar dichas zonas mediante estudio de AR, para lograr una mejor precisión de la patología. Cuando la colaboración del paciente lo permita, el estudio en AR debería realizarse en espiración (Figura 6). Creemos que este método de estudio dirigido nos dará la mayor información con la menor dosis de radiación posible.

Debe destacarse que los procesos infecciosos agudos en la niñez producen edema o exudado que llevaran a una disminución de calibre de la pequeña vía aérea con aumento de la resistencia y atrapamiento aéreo. Por tanto la TC para evaluar cuadros secuelares deben efectuarse en ausencia de estos.

Una manifestación radiológica poco destacada en publicaciones previas ${ }^{(17)}$ y que probablemente refleja una mayor agresividad del serotipo viral encontrada en nuestro país (7h), es la alta incidencia de atelectasia cicatrizal visible en 30 sitios y especialmente en los lóbulos superior derecho e inferior izquierdo, a los cuales se asocia un menor desarrollo de la vía aérea colateral.

Tanto el atrapamiento aéreo como las atelectasias cicatrizales son consecuencias directas de un mismo proceso, como lo es el compromiso fibroso peribronquiolar. Según la magnitud de este y el grado de obstrucción ya sea parcial o total se manifestara de distintas formas determinando hiperinsuflación o colapso obstructivo en el espacio aéreo periférico ${ }^{(6)}$. Algún grado de influencia en esta manifestación puede tener la vía aérea colateral. También la combinación de atelectasia y atrapamiento aéreo incidieron en la apreciación del volumen pulmonar, sin embargo este ocurrió principalmente en relación al pulmón con mayor presencia de atelectasias cicatrizales.

Las bronquiectasias definidas como dilatación irreversible de la vía aérea fueron evaluadas de acuerdo a criterios previamente definidos para su diagnóstico en TC ${ }^{(35)}$. Estos signos comprenden: el aumento del diámetro interno del bronquio, la mantención del calibre bronquial hacia la periferia y la visualización de bronquios en los $2 \mathrm{~cm}$ externos del pulmón. Signos indirectos de bronquiectasia en TC de alta resolución son, el engrosamiento de la pared bronquial, la impactación de bronquios dilatados (Figura 7) y el atrapamiento aéreo focal ${ }^{(36)}$.

La evaluación de estos signos es subjetiva y el diámetro bronquial, al no existir una medida determinada, es evaluado comparativamente con el de la arteria pulmonar que lo acompaña siendo normalmente ambos similares. Esto no esta exento de error, la orientación oblicua al plano de corte del 

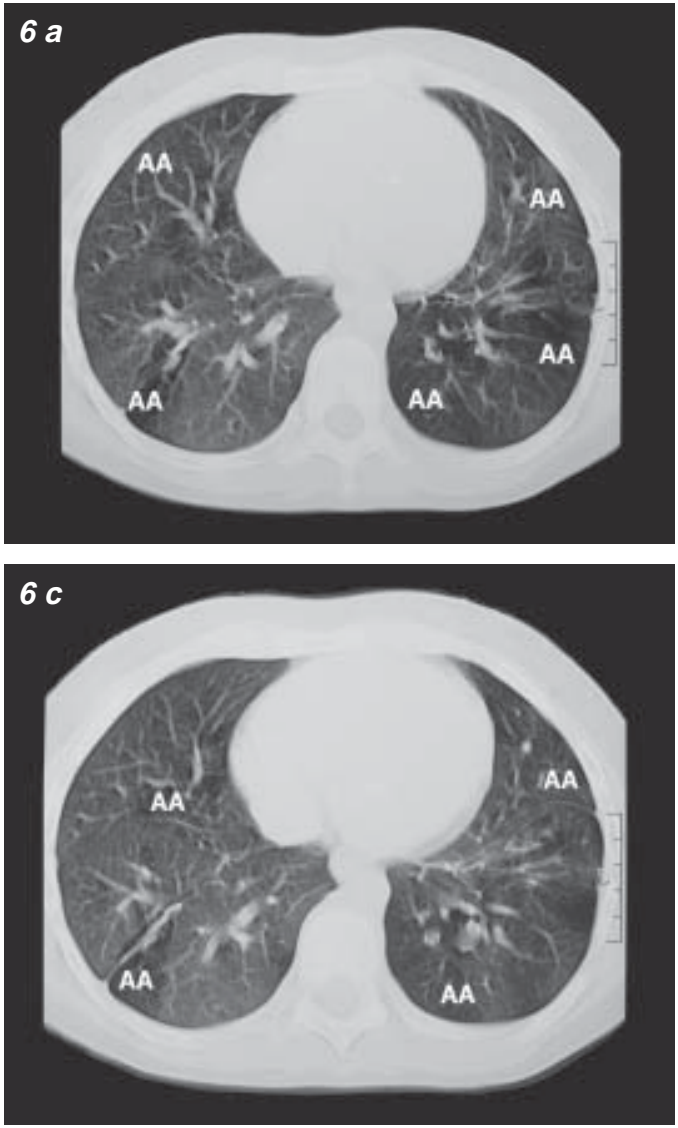
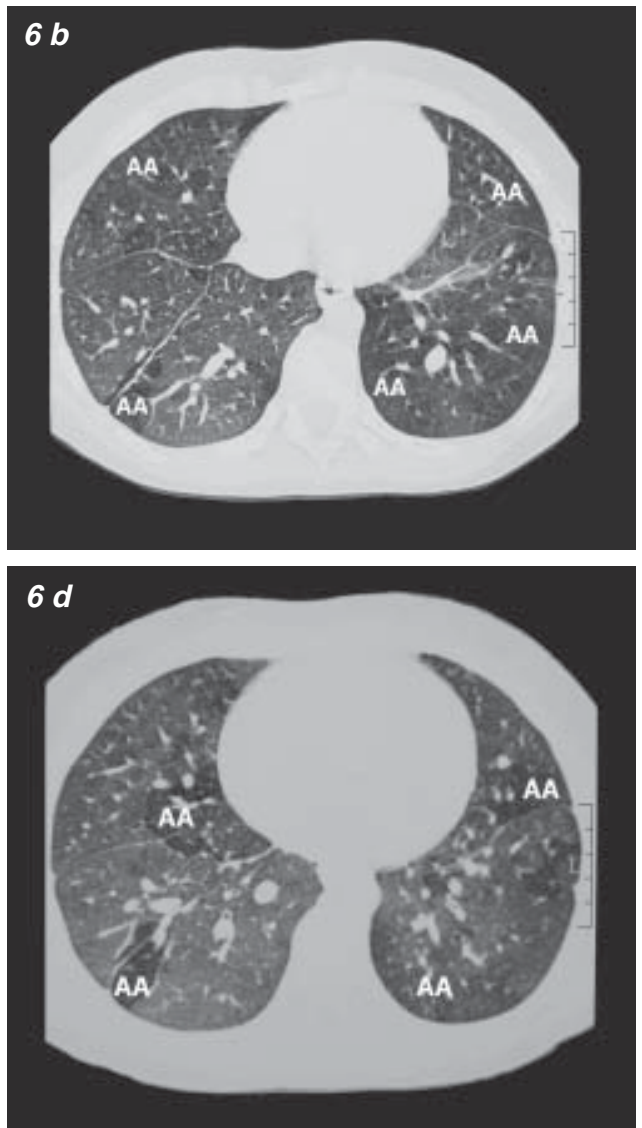

Figura 6 a,b,c,d. Paciente del sexo masculino de 11 años. a,b: Examen en inspiración a: TAC helicoidal, corte de 7 mm. b: Corte de $1 \mathrm{~mm}$ con algoritmo de reconstrucción de alta frecuencia espacial. c,d: Examen en espiración c: TAC helicoidal, corte de $7 \mathrm{~mm}$ d: Corte de $1 \mathrm{~mm}$ con reconstrucción igual que en $b$. Se identifican las zonas de atrapamiento aéreo (AA) que son mejor detectadas en espiración (cortes finos) y con algoritmo de reconstrucción de alta frecuencia espacial (d).

Figura 7. Paciente del sexo masculino de 1 año y 6 meses. Se identifican bronquiectasias (flechas cortas), impactación mucosa en bronquios en "dedo de guante" (punta de flechas), bronquioloectasia "arbol en brote" (flechas largas) y zonas de atrapamiento aéreo (AA). Obsérvese la línea de unión anterior prominente y levemente desplazada a izquierda.
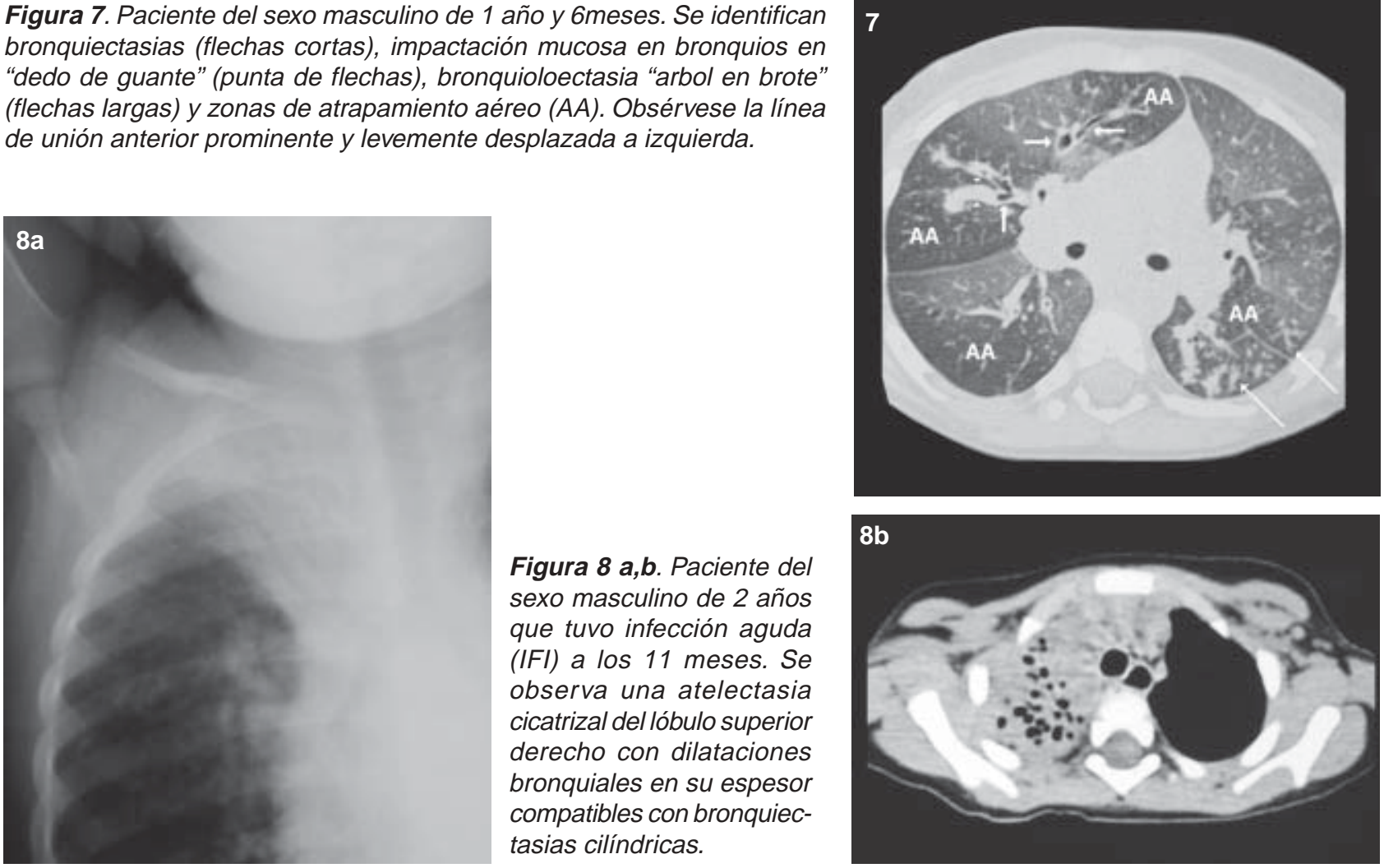

Figura 8 a,b. Paciente del sexo masculino de 2 años que tuvo infección aguda (IFI) a los 11 meses. Se observa una atelectasia cicatrizal del lóbulo superior derecho con dilataciones bronquiales en su espesor compatibles con bronquiectasias cilíndricas.

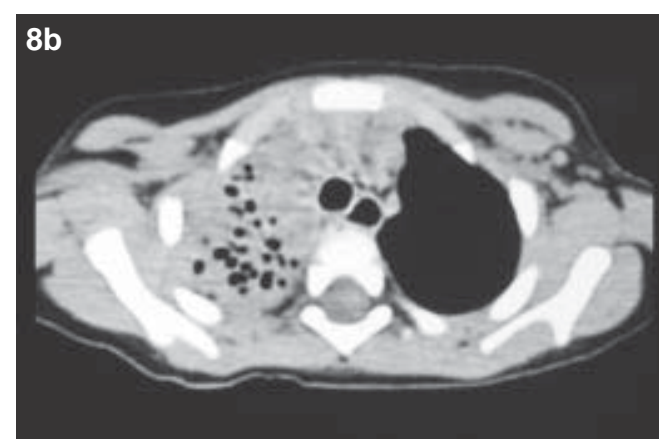


bronquio y arteria pueden alterar la apreciación del diámetro bronquial. Sin embargo, la falla más importante se puede producir por las alteraciones fisiológicas producidas por el atrapamiento aéreo, que acompaña a la bronquiolitis constrictiva, que lleva a una importante vasoconstricción y de esta forma a sobredimensionar el diámetro bronquial(36). Debe tenerse también en cuenta que en TC de niños resulta difícil diferenciar entre una leve dilatación bronquial reversible y una pequeña bronquiectasia cilíndrica ${ }^{(37)}$.

Las bronquiectasias fueron encontradas en 16 $(67 \%)$ de nuestros casos todas eran del tipo cilíndricas y en la mayoría de los casos asociadas a atelectasia cicatrizal (Figura 8), aun cuando también se observaron en segmentos no atelectasicos (Figura 7). Pueden ser manifestación primaria del compromiso viral o secundarias a infección sobreagregada lo cual no podemos descartar ya que el intervalo IFI-TAC fue de 2 a 144 meses, periodo en el cual pudieron ocurrir episodios infecciosos diferentes al adenovirus.

El engrosamiento peribronquial demostrado en todos los casos puede ser debido a un signo indirecto de bronquiectasia o a un compromiso de toda la vía aérea por la infección viral, pero que afectó principalmente a bronquiolos. Becroft en una revisión de los cambios histológicos en 5 casos de niños neozelandeses afectados por adenovirus del tipo 21 describen engrosamiento de las paredes bronquiales con diferentes grados de compromiso que variaban de alteraciones mucosas predominantes a una importante desorganización de toda la pared bronquial como se observa en las bronquiectasias( ${ }^{(6)}$. Alteraciones histológicas similares fueron descritas por este mismo autor para el tipo viral $7^{(21)}$.

En cinco de nuestros casos se detectaron pequeñas áreas de condensación y nódulos centrolobulillares todos ellos relacionados con toda probabilidad a cuadros infecciosos sobreagregados según la revisión de antecedentes clínicos.

No encontramos signos directos de BO constrictiva en nuestro estudio, lo que se explica probablemente por el pequeño tamaño del bronquiolo de nuestros pacientes, a ajustes técnicos y a la resolución de los equipos en este estudio retrospectivo.

El compromiso agudo en todos nuestros casos afectó principalmente a varones y se produjo antes de los 8 años, por tanto el compromiso se asimila al síndrome de Swyer-James. Tuvimos un caso de un niño de 9 años y 6 meses en el cual es importante destacar, que el daño pulmonar observado, fue menor que en el resto de los pacientes. Este último hallazgo se puede explicar dado que la afectación pulmonar por el virus, se produjo después de completado el desarrollo pulmonar en cuanto a número alvéolos y vía aérea y además hay una madurez fisiológica pulmonar en la hematosis y respuesta inmune.
La magnitud del daño bronquial y bronquiolar determinaran el curso clínico del paciente. Dado que gran parte de la resistencia al flujo de aire esta determinado por la vía aérea principal, debe existir un significativo compromiso de la vía aérea periférica para manifestarse en las pruebas de función pulmonar ${ }^{(22)}$. Por otra parte al ser el compromiso generalmente multifocal una biopsia abierta puede tomar zonas no afectadas De esta forma el examen tomográfico resulta útil tanto para su detección previo a las manifestaciones funcionales y para cuantificar el real compromiso morfológico.

\section{Conclusión}

Los hallazgos tomográficos de bronquiolitis constrictiva en niños, secundaria a infección por adenovirus, son similares a los descritos en el síndrome de Swyer-James que es la manifestación en radiología de tórax convencional, broncografía y angiocardiografía de esta patología. La mayor resolución de la TC, permite definir mejor los hallazgos y demuestra además que el compromiso siempre es bilateral.

Dada la existencia y la mayor agresividad del adenovirus $7 \mathrm{~h}$ en nuestro país y el cono sur de Sudamérica, pensamos que en los casos de bronquiolitis constrictiva demostrados; tanto en adultos como en niños; debe plantearse la posibilidad de esta enfermedad viral en la infancia. La comunicación del virus en otros países debe hacer pensar en su expansión.

De acuerdo a los resultados obtenidos, podemos afirmar que la historia clínica y los hallazgos de la TC, son suficientes para plantear el diagnóstico de BO constrictiva post-infecciosa.

Como todas las técnicas tomográficas, los parámetros técnicos deben ser ajustados al paciente pediátrico y deben obviarse complementos innecesarios cuando la patología esté demostrada.

\section{Bibliografía}

1. Wu E, Martínez V, Alvarez A, Larrañaga C, Vela H. Casos fatales de infección por adenovirus. Rev Chil Pediatr. 1990; 61: 177-184.

2. Santolaya ME, Henríquez A, Latorre JJ. Neumonía fatal por adenovirus. Rev Chil Pediatr 1989;60: 147-150.

3. Horwitz M. Adenoviruses In: Fields B.N., Knipe D.M. et al. Eds. Virology $2^{\text {nd }}$ Ed. New York. Raven Press, 1990.

4. Kajon A, Vicente M. Molecular epidemiology of adenovirus isolated from hospitalized children with severe lower acute respiratory infection in Santiago, Chile. J Med Virol 1990; 30: 294-297.

5. Similä S, Linna O, Lannig P. et al. Chronic lung damage caused by adenovirus 7: A ten years follow-up study. Chest 1981; 80: 127-131.

6. Becroft DM. Pulmonary sequelae of epidemic type 21 adenovirus infection: a 13-year follow-up. Arch Dis Child. 1979; 54: 155-156.

7. Lang W.R, Howden CD, Laws J, Burton J.F. 
Bronchopneumonia with serious sequelae in children with evidence of adenovirus type 21 infection. Brit Med J. 1969; 1: 73-79.

8. Sly PD, Soto-Quiros ME, Landau LI. et al. Factors predisposing to abnormal function after adenoviruses type 7 pneumonia. Arch Dis Child 1984; 59: 935-939.

9. Teper AM, Kofman CD, Maffey AF. et al. Lung function in infants with chronic pulmonary disease after severe adenoviral illness. J Pediatr 1999; 134: 730-733.

10. Straliotto SM, Siqueira MM, Muller RL. et al. Viral etiology of acute respiratory infections among children in Porto Alegre, RS, Brazil. Revista da Sociedade Brasileira de Medicina Tropical. 2002; 35; 283- 291.

11. Carballal G, Videla C, Misirlian A. et al. Adenovirus type 7 associated with severe and fatal acute lower respiratory infections in Argentine children. BMC Pediatrics 2002; 2:6.

12. Peluffo MH, Russi JC, Arbiza JR. y col. Infecciones respiratorias agudas en niños menores de 5 años hospitalizados. Revista Médica del Uruguay. 1986; 3: 213226.

13. Larrañaga C, Kajon A, Villagra E, Avendaño LF. Adenovirus surveillance on children hospitalized for acute lower respiratory infections in Chile (1988-1996). Journal of Medical Virology. 2000; 60: 342-346.

14. Palomino MA, Larrañaga C, Avendaño LF. Hospitalacquired adenovirus $7 \mathrm{~h}$ infantile respiratory infection in Chile. Pediatr Infect Dis 2000; 19: 527-531.

15. Marti-Bonmati L, Ruiz F, Catala F. et al. CT findings in Swyer-James syndrome. Radiology 1989; 172:477-480.

16. Moore AD, Godwin JD, Dietrich PA. et al. Swyer-James syndrome: CT findings in eight patients. AJR Am J Roentgenol 1992; 1211-1215.

17. Chang AB, Masel JP, Masters B. Post-infectious bronchiolitis obliterans: clinical, radiological and pulmonary function sequelae. Pediatr Radiol 1998; 28: 23-29.

18. Zhang L, Irion K, da Silva Porto N, Abreu e Silva F. HRCT in pediatric patients with post infectious bronchiolitis obliterans. J Thoracic Imaging 1999; 14: 85-89.

19. Kim Ch.K, Kim SW, Kim SW. et al. Bronchiolitis obliterans in the 1990s in Korea and the United States. Chest 2001; 120: 1101-1106.

20. Penn CC, Liu Ch. Bronchiolitis following infection in adults and children. Clinics in Chest Medicine 1993; 14: 645-654.

21. Becroft DM. Histopathology of fatal adenovirus infection of the respiratory tract in young children. J Clin Path. 1967; 20: 561-569.
22. Waitches GM, Stern EJ. High resolution CT of peripheral airways disease. Radiol Clinics of North Am. 2002; 40: 21-29.

23. Kajon A, Wadell G. Molecular epidemiology of adenoviruses associated with acute lower respiratory disease of children in Buenos Aires, Argentina (19841988). J Med Virol 1992; 36: 292-297.

24. Hashido M, Mukouyama A, Sakae K. et al. Molecular and serological characterization of adenovirus genome type $7 \mathrm{~h}$ isolated in Japan. Epidenmol Infect 1999; 122: 281-286.

25. Kaempfer AM., Medina E. Hospitalización infantil en Chile: Situación actual y perspectivas. Revista Chilena de Pediatría 63: 110-117.

26. Mistchenko AS, Diez RA, Mariani AL. et al. Cytokines in adenoviral disease in children: Association of interleukin-6, interleukin-8 and tumor necrosis factor alpha with clinical outcome. J Pediatr 1994; 124: 714720.

27. Maud T, Dohlnikoff M. Histology of chilhood bronchiolitis obliterans. Pediatr Pulmonology. 2000; 33: 466-474.

28. Fraser RS, Müller NI, Colman N, Paré P.D. en Fraser and Paré's: Diagnosis of diseases of the chest. 4 th edition. Volume 4, Chapter 58, pages 2337-2343. 1999, W.B. Saunders Company.

29. Colby TV. Bronchiolitis: Pathologic considerations. Am J Clin Pathol 1998; 109: 101-109.

30. Garg K, Newell JD, King Jr. TE. Proliferative and constrictive bronchiolitis: Classification and radiologic features. AJR Am J Roentgenol 1994; 162: 803-808.

31. Swyer PR, James GC. A case of unilateral pulmonary emphysema. Thorax 1953; 8:133-136.

32. Mac Leod WM. Abnormal transradiancy of one lung. Thorax 1954; 9: 147-152.

33. Webb WR, Stern EJ, Kanth N, Gamsu G. Dynamic pulmonary CT: findinds in healthy adult men. Radiology 1993; 186: 117-124.

34. Coakley F, Cohen MD, Johnson MS. et al. Detection of pulmonary metastasis with pathological correlation: Effect of breathing on the accuracy of spiral CT. Pediatr Radiol 1997; 27: 576-579.

35. Lynch DA., Newell J, Hale V. et al. Correlation of CT findings with clinical evaluation in 261 patients with symptomatic bronchiectasis. AJR Am J Roentgenol 1999; 173: 53-58.

36. Mc Guinnes G, Naidich D. CT of airways disease and bronchiectasis. Radiol Clin of North Am. 2002; 40:1-19.

37. Kuhn JP, Brody AS. High-resolution CT Of pediatric lung disease. Radiol Clinics of North Am. 2002; 40: 89-110. 